\title{
In defence of older drivers
}

\author{
Ezra Hauer PhD
}

$\mathrm{T}$ here comes a time in our lives when we curtail our driving; indeed, some of us will even have our driving privileges revoked. Physicians are asked to play a role in the delicensing process. This role should be based on fact, not prejudice. The aim of this paper is to separate the two.

A CMAJ editorial ${ }^{1}$ states that

[T] he ability to drive safely decreases with age, because of the growing list of medical conditions that can affect fitness to drive. For people over 65 years of age, the crash rate per kilometre travelled increases until, by age 75 , it surpasses that for teenage drivers.

This statement is misleading. If it refers to all reported crashes, it is incorrect. Using data from a study by Williams, ${ }^{2}$ which is similar to earlier results by Cerrelli, ${ }^{3}$ Figure 1 shows that the agerelated increase in the crash rate for older drivers is modest and does not surpass that for teenagers. Perhaps the claim in the editorial rests instead on the rate of fatal crashes shown in Figure 2, the rising right side of which is sometimes simplistically attributed to a decrease in the ability to drive safely due to medical conditions. ${ }^{4}$

The difference between Figures 1 and 2 is due to frailty - the age-related increase in the probability of dying as a result of a crash. Frailty as a cause of overrepresentation should not be confused with the ability to drive safely. If there is evidence of an alleged age-related decrease in the ability to drive safely, it should be sought in Figure 1. However, even the modest age-related increase seen in the figure is not attributable mainly to a decline in the ability to drive safely.

Seniors do a larger proportion of their driving on streets (as opposed to freeways) than do other drivers, ${ }^{5}$ and the crash rate in a network of streets with multiple intersections is much higher than on freeways. ${ }^{6}$ Therefore, part of the modest overrepresentation seen in Figure 1 reflects the kinds of roads on which seniors tend to drive, not the ability to drive safely. Furthermore, these data are from reported crashes. Not all crashes are reported. Crashes in which injuries occur are more fully reported than crashes in which only property is damaged, and seniors are more easily injured in a crash. In addition, seniors report their crashes more fully than do other drivers. ${ }^{7}$ Likewise, multivehicle crashes are more frequently reported than single-vehicle crashes, and seniors are involved in a higher number of multivehicle crashes than other drivers because of where they drive. For these reasons, a larger proportion of seniors' crashes end up in the official statistics; this too contributes to the appearance of overrepresentation and has nothing to do with the ability to drive safely.

When seniors are compared with nonsenior drivers who drive about the same amount, the overrepresentation disappears completely, except

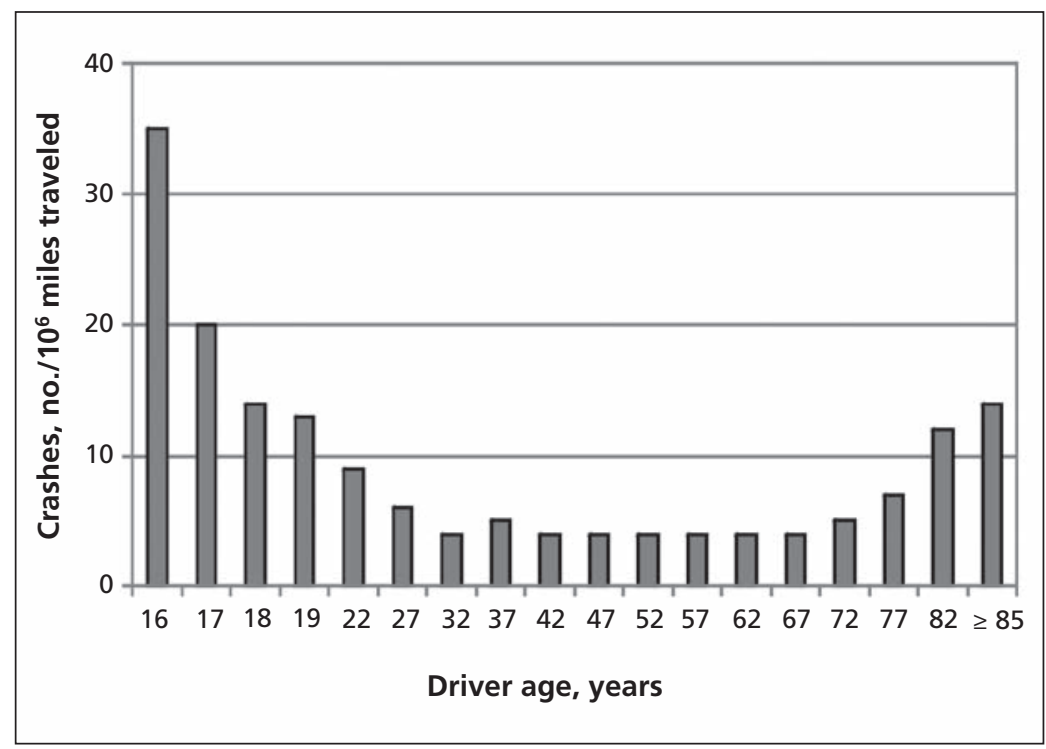

Figure 1: Involvement in crashes per million miles travelled by driver age. Reprinted from: Williams AF. Teenage drivers: patterns of risk. J Safety Res 2003;34:5-15, with permission from Elsevier.

\section{- KeY POINTS}

- Older drivers are overrepresented in fatal crashes, mainly owing to their frailty, not their ability to drive safely.

- When seniors are compared with nonseniors who drive the same amount, the overrepresentation disappears completely, except among people who drive fewer than 3000 kilometres per year.

- Unlike younger drivers, older drivers are a danger mainly to themselves. 
among people who drive fewer than 3000 kilometres per year. ${ }^{8}$ Eberhard says that

"[I]f there is an older driver safety problem it can only be found in those who drive few miles and these represent less than $10 \%$ of older drivers." 9

The chain of reasoning - that older drivers have an inordinately high risk of being in crashes due to a decline in their ability to drive safely, and that this decline is caused by age-related medical conditions - is but a house of cards. Without the false claim that older drivers have a very high probability of being involved in a crash, the structure collapses.

In addition, the number of people killed when an older person is driving is very small in comparison with other drivers. More than four-fifths of those killed when the driver is 85 years of age or older are the drivers themselves; among drivers

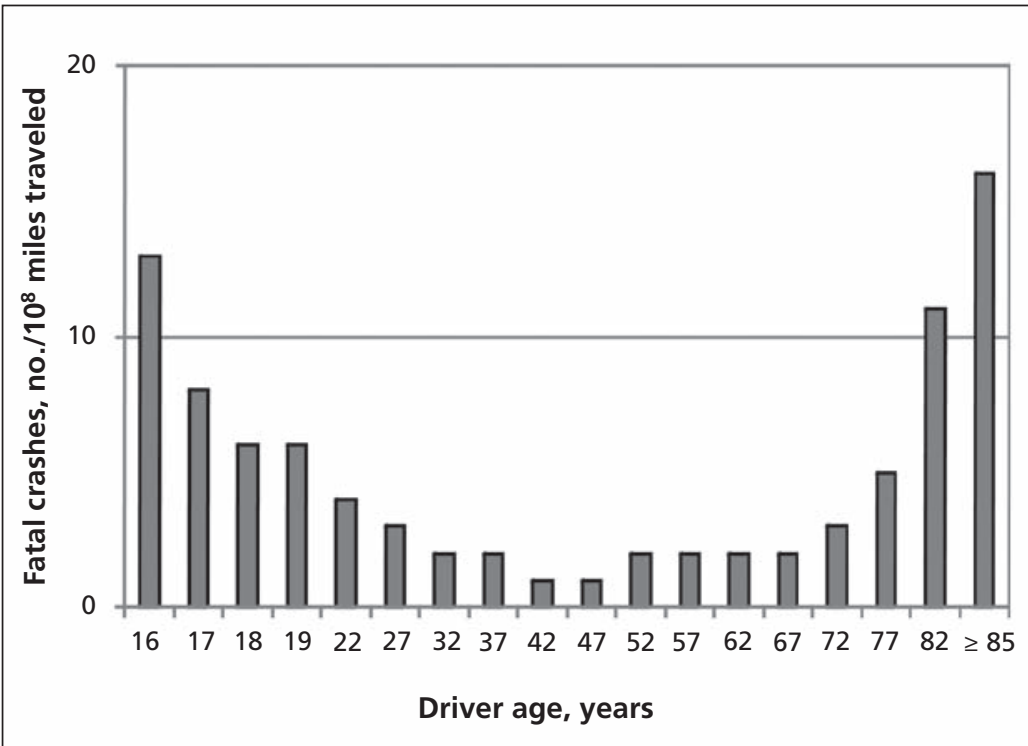

Figure 2: Involvement in fatal crashes per hundred million miles travelled by driver age. Reprinted from: Williams AF. Teenage drivers: patterns of risk. $J$ Safety Res 2003;34:5-15, with permission from Elsevier. between the ages of 16 and 59 years, two-thirds of those killed are other people. ${ }^{10}$ Unlike younger drivers, older drivers are a danger mainly to themselves.

In spite of what data show consistently, almost one-third of Canadians believe that elderly drivers are a "very or extremely serious traffic safety problem." "11 The CMAJ editorial ${ }^{1}$ echoes this prejudice, giving succour to government programs that rely on that prejudice for public support. However, medicine is an evidence-based discipline, and physicians should debate their role in the delicensing of drivers on the basis of facts, not lay beliefs.

\section{Rererences}

1. MacDonald N, Hébert PC. Driving retirement program for seniors: long overdue. CMAJ 2010;182:645.

2. Williams AF. Teenage drivers: patterns of risk. J Safety Res 2003; 34:5-15.

3. Cerrelli EC. Crash data and rates for age-sex groups of drivers, 1996. [research note].Washington (DC): National Highway Traffic Safety Administration; 1998.

4. Dobbs BM, Dobbs AR. The Medically at-risk driver - cognitive impairment leads the way. British Columbia Injury Prevention 2006 Conference. March 1 - 3, Vancouver. Available: www. injuryresearch.bc.ca/documents/Road $\% 20$ Safety $\% 20 \% 20$ Medically $\% 20$ at\%20Risk\%20Driver-\%20Cognitive\%20Impairment\%20.pdf (accessed 2011 June 5).

5. Benekohal, RF, Michaels, RM, Shim, E, et al. Effects of aging on older drivers' travel characteristics. Washington (DC): Transportation Research Board; 1994. p. 91-8.

6. Bureau of Transportation Statistics, Research and Innovative Technology Administration, USA. Table 2-18: Motor vehicle fatalities, vehicle miles and association rates by highway functional system. 2003. Washington (DC): The Bureau; 2003. Available: www.bts.gov/publications/national_transportation_statistics /2003/html/table_02_18.html (accessed 2011 Sept. 19).

7. Hauer E, Hakkert AS. Extent and some implications of incomplete accident reporting. Washington (DC): Transportation Research Board; 1989. p. 1-10.

8. Langford J, Methorst R, Hakamies-Blomqvist L. Older drivers do not have a high crash risk - a replication of low mileage bias. Accid Anal Prev 2006:38:574-8.

9. Eberhard J. Older drivers' "high per-mile crash involvement": the implications for licensing authorities. Traffic Inj Prev 2008;9:284-90.

10. Dellinger AM, Kresnow M-J, White DD, et al. Risk to self versus risk to others. How do older drivers compare to others on the road? Am J Prev Med 2004;26:217-21.

11. Robertson R, Vanlaar W. Elderly drivers: Future challenges? Accid Anal Prev 2008;40:1982-6.

Affiliation: Ezra Hauer is with the Department of Civil Engineering, University of Toronto, Toronto, Ont. 